\title{
Caveolin 3-mediated integrin $\beta 1$ signaling is required for the proliferation of folliculostellate cells in rat anterior pituitary gland under the influence of extracellular matrix
}

\author{
Kotaro Horiguchi, Ken Fujiwara, Cimi Ilmiawati, Motoshi Kikuchi, Takehiro Tsukada, Tom Kouki \\ and Takashi Yashiro \\ Division of Histology and Cell Biology, Department of Anatomy, Jichi Medical University School of Medicine, 3311-1 Yakushiji, Shimotsuke, \\ Tochigi 329-0498, Japan \\ (Correspondence should be addressed to K Horiguchi; Email: kota@jichi.ac.jp; T Yashiro; Email: tyashiro@jichi.ac.jp)
}

\begin{abstract}
Folliculostellate (FS) cells in the anterior pituitary gland are believed to have multifunctional properties. Using transgenic rats that express green fluorescent protein (GFP) specifically in FS cells in the anterior pituitary gland (S100b-GFP rats), we recently revealed that FS cells in primary culture exhibited marked proliferation in the presence of laminin, an extracellular matrix (ECM) component of the basement membrane. In a process referred to as matricrine action, FS cells receive ECM as a signal through their receptors, which results in morphological and functional changes. In this study, we investigated matricrine signaling in FS cells and observed that the proliferation of FS cells is mediated by integrin $\beta 1$, which is involved in various signaling pathways for cell migration and proliferation in response to ECM. Then, we

analyzed downstream events of the integrin $\beta 1$ signaling pathway in the proliferation of FS cells and identified caveolin 3 as a potential candidate molecule. Caveolin 3 is a membrane protein that binds cholesterol and a number of signaling molecules that interact with integrin $\beta 1$. Using specific small interfering RNA of caveolin 3, the proliferation of FS cells was inhibited. Furthermore, caveolin 3 drove activation of the mitogen-activated protein kinase (MAPK) signaling cascades, which resulted in upregulation of cyclin D1 in FS cells. These findings suggest that matricrine signaling in the proliferation of FS cells was transduced by a caveolin 3-mediated integrin $\beta 1$ signaling pathway and subsequent activation of the MAPK pathway.

Journal of Endocrinology (2011) 210, 29-36
\end{abstract}

\section{Introduction}

The anterior pituitary gland is composed of five types of hormone-producing cells and folliculostellate (FS) cells that do not produce classical anterior pituitary hormones. These cell aggregations form cell cords or clusters surrounded by different types of extracellular matrices (ECM) that provide the mechanical integrity, rigidity, and elasticity that are essential for these cells to perform their respective roles (Soji \& Herbert 1989, Kaidzu et al. 2000, Paez-Pereda et al. 2005). FS cells have a star-like appearance and form a pseudolumen at the central portion of FS cell clusters (Soji \& Herbert 1989). Physiologically, it has been speculated that FS cells may be stem cells, phagocytes, or regulating cells for hormone release (Allaerts \& Vankelecom 2005) and that they accomplish cell-to-cell communication via the gap junction in the anterior pituitary gland (Fauquier et al. 2001, Sato et al. 2005).

Generally, cells can receive ECM as a signal that causes changes such as migration, proliferation, and differentiation - a process referred to as 'matricrine' action (Miyamoto et al. 2007). In our recent attempt to investigate matricrine action in anterior pituitary cells, FS cells markedly extended their cytoplasmic processes and promoted gap junction formation between them under the influence of laminin that is an ECM component of the basement membrane (Horiguchi et al. 2010, 2011). In addition, we showed that FS cells exhibited marked proliferation in the presence of ECM (Horiguchi et al. 2010). However, it is unclear at present how FS cells receive laminin as a signal and exhibit these phenomena, which is crucial for understanding matricrine action in FS cells. In this study, we, therefore, attempted to determine the matricrine signaling pathway in the proliferation of FS cells. First, we examined whether proliferation of FS cells in the presence of laminin is mediated by integrin $\beta 1$ as a laminin receptor. Then, we analyzed the downstream events of the integrin $\beta 1$ signaling pathway with mediation by caveolin (Echarri et al. 2007), which is a membrane protein that binds cholesterol and a number of signaling molecules potentially linked with integrin function. 


\section{Materials and Methods}

\section{Animals}

Transgenic S100b-green fluorescent protein (GFP) rats express GFP under control of the promoter of the S100b protein gene, a marker of FS cells. The rats were donated by Prof. K Inoue of Saitama University and were bred in our laboratory (Itakura et al. 2007). Male rats aged 8-10 weeks weighing $250-300 \mathrm{~g}$ were given ad libitum access to food and water and housed under conditions of $12 \mathrm{~h}$ light: $12 \mathrm{~h}$ darkness. The rats were killed by exsanguination from the right atrium under deep Nembutal anesthesia and were then perfused with $\mathrm{Ca}^{2+}$ - and $\mathrm{Mg}^{2+}$-free Hank's solution for primary culture. All animals were treated in accordance with the Guidelines for Animal Experimentation of Jichi Medical University, which are based on the NIH Guidelines for the Care and Use of Laboratory Animals.

\section{Cell culture}

Anterior pituitary cells of male S100b-GFP rats were dispersed as described previously (Horiguchi et al. 2008). Dispersed cells were separated into GFP-positive and -negative cells by a cell sorter (MoFlo XDP: Beckman Coulter, Inc., Fullerton, CA, USA). GFP-positive cells were plated onto 8 -well glass chamber slides $\left(1 \mathrm{~cm}^{2} /\right.$ well; Nalge Nunc International, Rochester, NY, USA), with or without a coating of $10 \mu \mathrm{g} / \mathrm{cm}^{2}$ of laminin (Millipore, Bedford, MA, USA), at a density of $1 \times 10^{5} \mathrm{cells} / \mathrm{cm}^{2}$ in $400 \mu \mathrm{l}$ of Medium 199 with Earle's salts (Invitrogen) supplemented with 10\% FBS (Sigma-Aldrich Corp.), $0.5 \mathrm{U} / \mathrm{ml}$ penicillin, and $0.5 \mu \mathrm{g} / \mathrm{ml}$ streptomycin (Invitrogen). In the other experimental group, laminin-coated slides were treated in medium containing $5 \mu \mathrm{g} / \mathrm{ml}$ monoclonal anti-integrin $\beta 1$ antibody (clone Ha2/5, BD Biosciences, San Jose, CA, USA), which was shown to block signaling mediated by integrin $\beta 1$ (Schultz \& Armant 1995); hamster IgM served as control. Cells were then cultured for $72 \mathrm{~h}$ at $37^{\circ} \mathrm{C}$ in a humidified atmosphere of $5 \% \mathrm{CO}_{2}$ and $95 \%$ air.

\section{Proliferation assay}

To visualize the proliferative activities of FS cells, the nucleotide analog 5-bromo-2'-deoxyuridine (BrdU; SigmaAldrich Corp.) was added to primary culture for $24 \mathrm{~h}$ at a concentration of $3 \mu \mathrm{g} / \mathrm{ml}$. Cells were fixed in $4 \%$ paraformaldehyde in $25 \mathrm{mM}$ phosphate buffer (pH 7.4) for $20 \mathrm{~min}$ at room temperature and were then treated with $4 \mathrm{M} \mathrm{HCl}$ in PBS for $10 \mathrm{~min}$. Cells were incubated in PBS containing $2 \%$ normal goat serum for $1 \mathrm{~h}$ at $30^{\circ} \mathrm{C}$ and were then incubated with anti-rat BrdU mouse monoclonal antibody $(1.5 \mu \mathrm{g} / \mathrm{ml}$, Sigma-Aldrich Corp.) for $90 \mathrm{~min}$ at $30^{\circ} \mathrm{C}$. After washing with PBS, cells were incubated in PBS with Alexa Fluor 568conjugated goat anti-mouse $\operatorname{IgG}$ (Invitrogen) diluted to 1:200. The absence of an observable nonspecific reaction was confirmed using normal mouse serum. In total, ten random fields were imaged per well using a confocal laser microscope with a 60 -fold objective lens. The percentage of immunoreactive cells was calculated by counting at least 100 cells/well. The observations were done three times for each experimental group.

\section{Immunoblot analysis}

After primary culture, cells were washed in PBS and lysed in RIPA buffer $(20 \mathrm{mM}$ Tris, $150 \mathrm{mM} \mathrm{NaCl}, 2 \mathrm{mM}$ EDTA, $0 \cdot 1 \% \mathrm{w} / \mathrm{v}$ SDS, and $1 \% \mathrm{v} / \mathrm{v}$ Triton $\mathrm{X}-100, \mathrm{pH} 7 \cdot 5$ ), and total protein was estimated by using the Bradford assay reagent (Sigma). From each sample, $20 \mu \mathrm{g}$ protein was applied to $12 \%$ SDS-PAGE. Proteins were then electrophoretically transferred to Immobilon-P transfer membrane (Millipore). The membrane was blocked with $5 \%(\mathrm{w} / \mathrm{v})$ nonfat dried milk in TBST (50 mM Tris, $100 \mathrm{mM} \mathrm{NaCl,} \mathrm{0 \cdot 1 \%} \mathrm{v/v} \mathrm{Tween} \mathrm{20,} \mathrm{pH}$ 7.4) for $1 \mathrm{~h}$. After washing with TBST, the membrane was incubated overnight with mouse monoclonal caveolin 1 $(12.5 \mathrm{ng} / \mathrm{ml}$; BD Biosciences) or caveolin $3(5 \mathrm{ng} / \mathrm{ml}$; BD Biosciences), or rabbit polyclonal cyclin D1 (1:2000; NeoMarkers, Inc., Fremont, CA, USA), ERK1/2 (1:3000; Assay Designs, Ann Arbor, MI, USA), or phospho-ERK1/2 (1:5000; R\&D Systems, Inc., Minneapolis, MN, USA) antibody, diluted in Can Get Signal solution (Toyobo, Osaka, Japan), followed by TBST washes, and incubated for $1 \mathrm{~h}$ with HRP-labeled secondary antibodies (Envision + System-HRP, anti-rabbit, Dako, Glostrup, Denmark). After washing with TBST, specific immunoreactivity was visualized using Chemiluminescence ECL Plus Systems (GE Healthcare, Mississauga, ON, Canada) with lumi-shot film (Fujifilm, Tokyo, Japan). The film was scanned and densitometric analysis was performed with ImageJ software (NIH, Bethesda, MD, USA). The results were normalized with $\beta$-actin. Each analysis was performed in triplicate.

\section{Quantification of $m R N A$ levels by real-time reverse transcription-PCR}

Total RNA fractions were prepared with Trizol (Invitrogen) from cultured cells and incubated with RNase-free DNase I (1 U/tube; Promega Corp.). After inactivation of DNase I by heating for $10 \mathrm{~min}$ at $65{ }^{\circ} \mathrm{C}$, cDNA was synthesized using the PrimeScript RT reagent kit (Takara, Otsu, Japan) with oligo$(\mathrm{dT})_{20}$ primer (Invitrogen). Quantitative real-time PCR (ABI PRISM 7900HT; Applied Biosystems, Carlsbad, CA, USA) was performed by using gene-specific primers and SYBR Premix Ex Taq (Takara) containing SYBR Green I. The following primers were used to amplify cDNA fragments of cyclin D1 (GenBank accession no. NM_171992): forward $5^{\prime}$-TGCAAATGGAACTGCTTCTG- $3^{\prime}$ and reverse $5^{\prime}$-GCGGATGATCTGCTTGTTCT-3' (125 bp); caveolin 1 (NM_031556): forward 5'-GGGAACAGGGCAACATCTAC- $3^{\prime}$ and reverse $5^{\prime}$-GCGGTTGACCAGATCAATTT-3' (107 bp); caveolin 2 (NM_131914): forward 
5'-GGATCTGATCGCAGAACCTC- $3^{\prime}$ and reverse $5^{\prime}$-CAAGGGGATGGCTAGAAACA-3' (127 bp); caveolin 3 (NM_019155): forward 5'-GGTGAACAGAGACCCCAAGA- $3^{\prime}$ and reverse $5^{\prime}$-ACGCCATCGAAGCTGTAAGT- $3^{\prime}$ (99 bp). For normalization, we also quantified glyceraldehyde 3-phosphate dehydrogenase (GAPDH, M_17701): forward $5^{\prime}$-AAGGGCTCATGACCACAGTC- $3^{\prime}$ and reverse $5^{\prime}$-GGATGCAGGGATGATGTTCT-3' (116 bp). Relative quantification was conducted using the standard curve method and was performed at least three times.

\section{Induction of caveolae depletion}

The GFP-positive cells were cultured for $72 \mathrm{~h}$ on the laminincoated surface as described above. The culture medium was changed to $400 \mu \mathrm{l}$ Medium 199 with Earle's salts (Invitrogen) supplemented with 10\% FBS (Sigma-Aldrich Corp.), $0.5 \mathrm{U} / \mathrm{ml}$ penicillin, $0.5 \mu \mathrm{g} / \mathrm{ml}$ streptomycin (Invitrogen), and $10 \mathrm{mM}$ methyl- $\beta$-cyclodextrin (M $\beta \mathrm{CD}$; WAKO, Osaka, Japan; Bellott et al. 2005, Chung et al. 2009) and cultured for $8 \mathrm{~h}$. M $\beta C D$ was used at a concentration of $10 \mathrm{mM}$ because this concentration has been shown to markedly disrupt caveolae structure in cultured cells, without affecting cell viability, by removing cholesterol from the plasma membrane (UshioFukai et al. 2001). After washing with Medium 199, the culture medium was changed without $\mathrm{M} \beta \mathrm{CD}$ for $40 \mathrm{~h}$. The culture medium without $\mathrm{M} \beta \mathrm{CD}$ was used as a negative control. We time-lapse recorded the cells as described previously (Horiguchi et al. 2010, 2011) using a digital camera (ORCAER; Hamamatsu Photonics, Shizuoka, Japan) and MetaMorph software (Molecular Devices Corp., Downingtown, PA, USA). Each observation was performed in triplicate.

\section{Small interfering RNA for caveolin 1 and 3}

For small interfering RNA (siRNA) transfection, the culture medium was replaced by $400 \mu \mathrm{l}$ Medium 199 with Earle's salts (Invitrogen) supplemented with 10\% FBS (Sigma-Aldrich Corp.), $0.5 \mathrm{U} / \mathrm{ml}$ penicillin, $0.5 \mu \mathrm{g} / \mathrm{ml}$ streptomycin (Invitrogen), siRNA against caveolin 1 or 3 mRNA $(0 \cdot 2 \mu \mathrm{M}$, Qiagen), and INTERFER in (1:100 v/v, PolyPlus Transfections, Inc., New York, NY, USA) transfection reagent at $24 \mathrm{~h}$. Nonsilencing siRNA (Qiagen) with no homology to any known mammalian gene was used as a negative control. After that, the GFP-positive cells were cultured for $48 \mathrm{~h}$. Each analysis was performed at least three times.

\section{Immunocytochemistry}

Cultured cells fixed with $4 \%$ paraformaldehyde in $50 \mathrm{mM}$ phosphate buffer for $20 \mathrm{~min}$ at room temperature were first immersed in PBS containing 2\% normal goat serum for $20 \mathrm{~min}$ at $30^{\circ} \mathrm{C}$ and then incubated overnight with anti-rat caveolin 3 mouse monoclonal antibody $(12.5 \mathrm{ng} / \mathrm{ml}$, BD Biosciences) at room temperature. After washing with PBS, cells were incubated in PBS with Alexa Fluor 568-conjugated goat anti-mouse $\operatorname{IgG}$ diluted to 1:200. Absence of an observable nonspecific reaction was confirmed using normal mouse serum. Cells were scanned using a confocal laser microscope (FV1000, Olympus Corp., Tokyo, Japan).

\section{Immunohistochemistry}

Pituitary glands were carefully excised and fixed overnight in $4 \%$ paraformaldehyde in $50 \mathrm{mM}$ phosphate buffer ( $\mathrm{pH} 7 \cdot 4$ ) at $4{ }^{\circ} \mathrm{C}$. Tissues were then immersed in phosphate buffer (pH 7.2) containing $30 \%$ sucrose for 2 days at $4{ }^{\circ} \mathrm{C}$, embedded in Tissue-Tek OCT compound (Sakura Finetechnical, Tokyo, Japan), and frozen rapidly. Frozen frontal sections (8 $\mu \mathrm{m}$ thick) were obtained using a cryostat (CM3000; Leica Microsystems, Wetzlar, Germany) and were mounted on slide glasses. Sections were incubated in PBS containing 2\% normal goat serum for $20 \mathrm{~min}$ at $30^{\circ} \mathrm{C}$ and were then incubated overnight with mouse anti-rat caveolin 3 monoclonal antibody $(12.5 \mathrm{ng} / \mathrm{ml}$; BD Biosciences) at room temperature. After washing with PBS, sections were incubated in PBS with Alexa Fluor 568-conjugated goat anti-mouse IgG (Invitrogen) diluted to 1:200 and were washed with PBS again. Sections were scanned using a confocal laser microscope.

\section{Statistical analysis}

All results were presented as mean \pm S.E.M. Statistical analysis was performed using ANOVA with Fisher's protected least significant difference test (StatView 5.0 software, SAS Institute, Inc., Cary, NC, USA) and Dunnett's test. Differences between groups were considered to be statistically significant at a $P$ value of $<0 \cdot 05$.

\section{Results}

\section{Role of integrin $\beta 1$ in laminin-induced FS cell proliferation}

A cell sorter was used to isolate FS cells from male S100bGFP rat anterior pituitary for primary culture. The histological features of FS cells in primary culture were the same as in our previous study (Horiguchi et al. 2011). At $72 \mathrm{~h}$, FS cells on the uncoated surface and laminincoated surface with integrin $\beta 1$ antibody formed clusters of $\sim 10-20$ cells (Fig. 1A and C). However, almost all FS cells on laminin with or without hamster IgM were flattened and had interconnected cell bodies (Fig. 1B and D). The percentage of BrdU-positive cells among all FS cells was $14.9 \pm 0.7$ and $13.9 \pm 0.5 \%$ on the laminin-coated surface with and without hamster IgM respectively (Figs 1J, L and 2A). In contrast, BrdU-positive FS cells were not observed on laminin-coated surfaces with integrin $\beta 1$ antibody or on uncoated surface (Figs 1I, K, and 2A). Then, we examined whether ERK activation and cyclin D1 expression level were regulated by integrin $\beta 1$. Using western blot analysis, we detected pERK, ERK, and cyclin D1 immunoreactivity, 


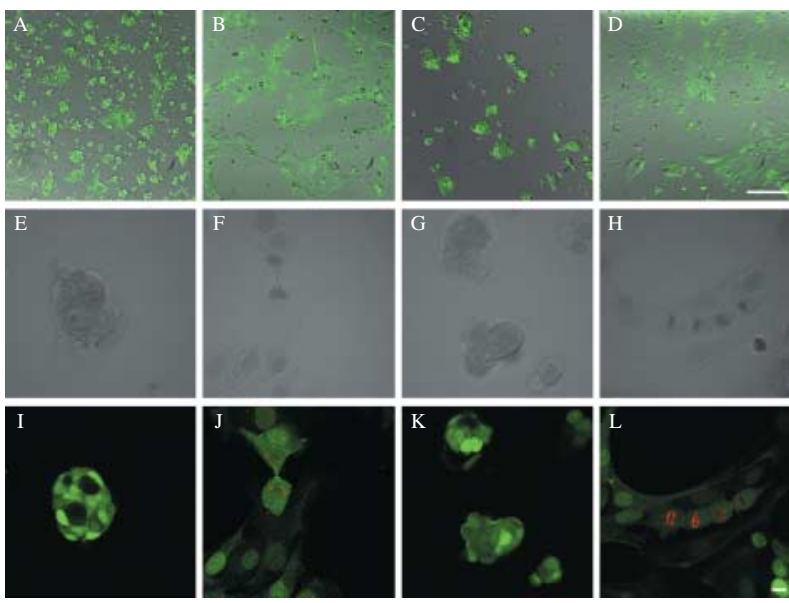

Figure 1 Proliferation of FS cells in primary culture. (A-D) GFP images superimposed on phase-contrast images on the uncoated surface, laminin-coated surface, laminin-coated surface with integrin $\beta 1$ antibody, and laminin-coated surface with hamster IgM respectively. Scale bars, $100 \mu \mathrm{m}$. (E-H) Phase-contrast image of the same field shown in $\mathrm{I}-\mathrm{L}$ on the uncoated surface, laminin-coated surface, laminin-coated surface with integrin $\beta 1$ antibody, and laminin-coated surface with hamster IgM respectively. (I-L) Confocal image of BrdU incorporation (green, FS cells and red, BrdU).

at their expected masses, in FS cells (Fig. 2B). When normalized with $\beta$-actin, the phosphorylation of ERK and the production of cyclin D1 were greater in FS cells on laminin-coated surfaces with or without hamster IgM than on the uncoated and laminin-coated surfaces with integrin $\beta 1$ antibody (Fig. 2C and D).

\section{Change in caveolin $m R N A$ and protein expression level in FS} cells on laminin

To determine whether laminin affects gene expression of caveolins in FS cells, we performed quantitative real-time RT-PCR. As compared with the uncoated surface, caveolin 1 and 3 expression was higher in FS cells on the laminin-coated surface (Fig. 3A and C). However, their expression levels on the laminin-coated surface with anti-integrin $\beta 1$ antibody were lower than those on the laminin-coated surface with hamster IgM. Caveolin 2 expression was not higher in cells on the laminin-coated surface compared with the uncoated surface (Fig. 3B). On western blot analysis, caveolin 1 and 3 immunoreactivity was greater in FS cells on the laminincoated surface (Fig. 3D-F). In contrast, treatment with antiintegrin $\beta 1$ antibody completely blocked the increases in caveolin 1 and 3 immunoreactivity in FS cells on the laminincoated surface with hamster IgM (Fig. 3D-F).

Time-lapse imaging of FS cells in primary culture with $M \beta C D$

To examine the importance of caveolin protein in the proliferation of FS cells under the influence of laminin, FS cells were exposed to $\mathrm{M} \beta \mathrm{CD}$, a cholesterol-depleting agent that disassembles caveolae (Bellott et al. 2005, Chung et al. 2009), from 72 to $80 \mathrm{~h}$ in primary culture. $\mathrm{M} \beta \mathrm{CD}$ treatment inhibited proliferation of FS cells (Fig. 4A, B and Supplementary Movie 1, see section on supplementary data given at the end of this article). After M $B C D$ was removed from medium in primary culture at $80 \mathrm{~h}$, FS cells resumed proliferation (Fig. 4C and Supplementary Movie 2, see
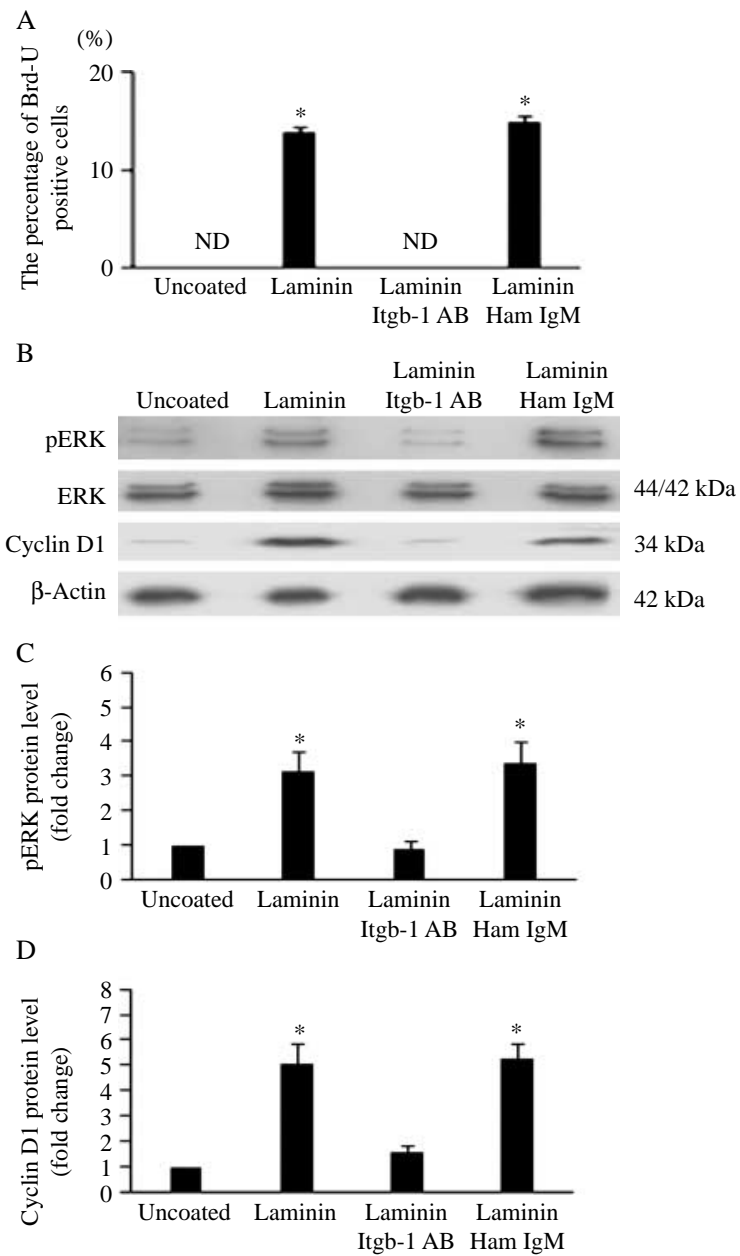

Figure 2 Analysis of proliferation of FS cells in primary culture. (A) Percentage of BrdU-positive cells among FS cells on the uncoated surface (uncoated), laminin-coated surface (laminin), laminin-coated surface with integrin $\beta 1$ antibody (laminin Itgb-1 $A B)$, and laminin-coated surface with hamster IgM (laminin Ham IgM). ND, not determined. (B) The amount of protein was determined by western blotting. The four panels show pERK, ERK, cyclin D1, and $\beta$-actin. (C and D) pERK and cyclin D1 protein levels in FS cells on the uncoated surface (uncoated), laminin-coated surface (laminin), laminin-coated surface with integrin $\beta 1$ antibody (laminin Itgb-1 AB), and laminin-coated surface with hamster IgM (laminin Ham IgM) respectively. Western blotting data from three experiments (mean \pm S.E.M., $n=3$ ) were quantified by densitometry and normalized with $\beta$-actin. pERK and cyclin D1 protein levels were calculated as ratios of uncoated values respectively. ${ }^{*} P<0 \cdot 05$. 


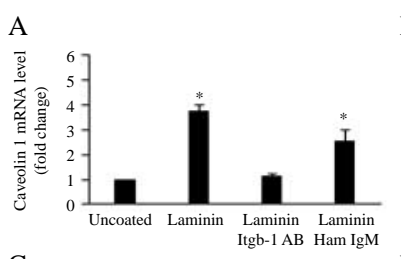

C
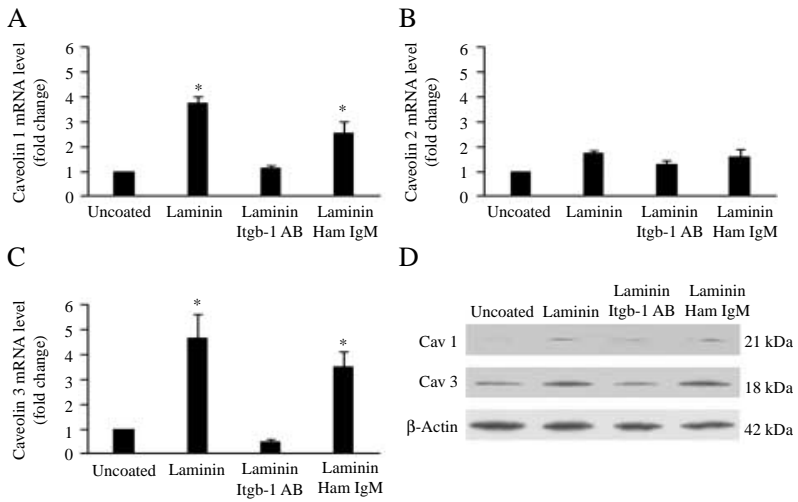

$\mathrm{E}$

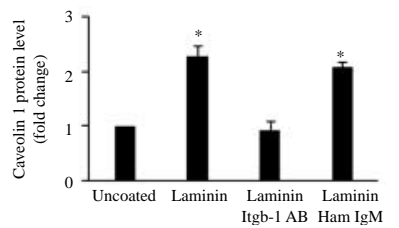

F

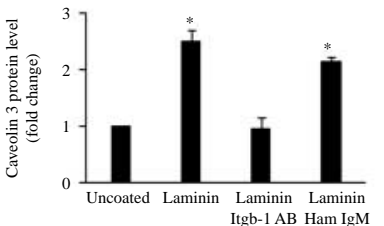

Figure 3 Caveolin expression levels in primary culture of FS cells after 72-h incubation. (A-C) The expression of caveolin 1, 2, and 3 mRNA determined by real-time PCR was normalized with an internal control (GAPDH) respectively (mean \pm S.E.M., $n=5$ ). Caveolin 1, 2, and 3 mRNA levels were calculated as ratios of uncoated values respectively. Caveolin 1 and 3 mRNA expression on the laminin-coated surface (laminin) and laminin-coated surface with hamster IgM (laminin Ham IgM) was higher than that on the uncoated surface (uncoated). (D) The amount of protein was determined by western blotting. The three panels show caveolin 1 (Cav 1), caveolin 3 (Cav 3), and $\beta$-actin. (E and F) Caveolin 1 and 3 protein levels in FS cells on the uncoated surface (uncoated), laminin-coated surface (laminin), laminin-coated surface with integrin $\beta 1$ antibody (laminin Itgb-1 AB), and laminin-coated surface with hamster IgM (laminin Ham IgM) respectively. Western blotting data from three experiments (mean \pm s.E.M., $n=3$ ) were quantified by densitometry and normalized with $\beta$-actin. Caveolin 1 and 3 protein levels were calculated as ratios of uncoated values respectively. ${ }^{*} P<0 \cdot 05$.

section on supplementary data given at the end of this article). However, FS cells on a laminin-coated surface without $\mathrm{M} \beta \mathrm{CD}$ from 72 to $120 \mathrm{~h}$ continued proliferating (Fig. 4D-F).

\section{Knockdown of caveolin 1 and 3 by siRNA}

To examine the functional role of caveolin 1 and 3 in the proliferation of FS cells, we downregulated caveolin 1 and 3 gene expression using siRNA in FS cells of primary culture on laminin-coated surfaces. When caveolin 1 and 3 were downregulated with a specific siRNA, their respective expression levels were also downregulated (Fig. 5A-D). Quantitative analysis revealed that cyclin D1 mRNA level in caveolin 3 siRNA-treated FS cells was lower than that in caveolin 1 siRNA-treated and control FS cells (Fig. 5E). The percentage of BrdU-positive cells among caveolin 3 siRNAtreated FS cells was also lower than that among caveolin 1 siRNA-treated and control FS cells (Fig. 5F).

\section{Localization of caveolin 3 on FS cells}

We examined the localization of caveolin 3 by immunocytochemistry at $72 \mathrm{~h}$ in primary culture on both the uncoated and the laminin-coated surfaces. Immunoreactive caveolin 3 was located on cell bodies and cytoplasmic processes at FS cells on both the uncoated and the laminincoated surfaces (Fig. 6A-D). Caveolin 3 immunoreactivity of FS cells was clearly greater on the laminin-coated surface than on the uncoated surface (Fig. 6B and D). We also detected the localization of caveolin 3 by immunohistochemistry in rat anterior pituitary gland. Immunoreactive caveolin 3 was located on FS cells in the anterior pituitary gland (Fig. 6E).

\section{Discussion}

In this study, we revealed that matricrine signaling of the proliferation in FS cells was transduced by the association of caveolin 3 with integrin $\beta 1$, which promotes mitogenactivated protein kinase (MAPK).

By using transgenic rats (S100b-GFP rats) that express GFP specifically in FS cells in the anterior pituitary gland (Itakura et al. 2007), we were able to use a cell sorter to obtain pure GFP-positive FS cells, which allowed us to examine the direct involvement of ECM on FS cells. As shown in Fig. 1, isolated FS cells directly receive laminin as a signal and thus proliferate in the absence of GFP-negative cells, which are primarily hormone-producing cells.

ECM generally transduces signals to cells through a family of transmembrane receptors called integrins (Hynes 2002). Many reports suggest that integrin signaling induces proliferation of cells, including mesangial cells, mammary
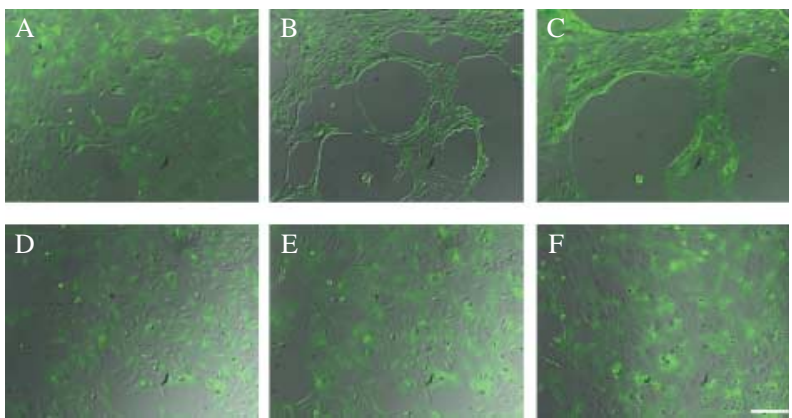

Figure 4 Time-lapse images of FS cells isolated from male S100bGFP rat anterior pituitary cells in primary culture on laminin-coated surface with or without $10 \mu \mathrm{M} M \beta C D$. Cells were time-lapse recorded at $15 \mathrm{~min}$ intervals from 72 to $120 \mathrm{~h}$ after cells were plated. (A-F) GFP images superimposed on phase-contrast images on the laminin-coated surface. (A) $72 \mathrm{~h}$, (B) $80 \mathrm{~h}$ of the same field shown in $72 \mathrm{~h}$ with MBCD for $8 \mathrm{~h}$ incubation. (C) $120 \mathrm{~h}$ of the same field shown in $80 \mathrm{~h}$, after $M \beta C D$ was removed for $40 \mathrm{~h}$ incubation. (D-F) 72,80 , and $120 \mathrm{~h}$ without M $\beta C D$. The elapsed time from plating of cells was 72,80 , and $120 \mathrm{~h}$ respectively. Scale bar, $100 \mu \mathrm{m}$. 


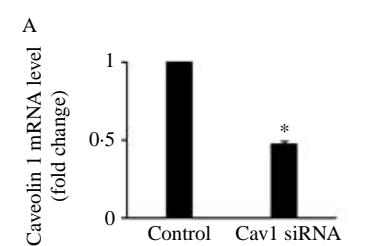

C Control Cav1 siRNA
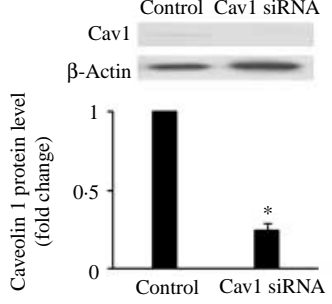

E
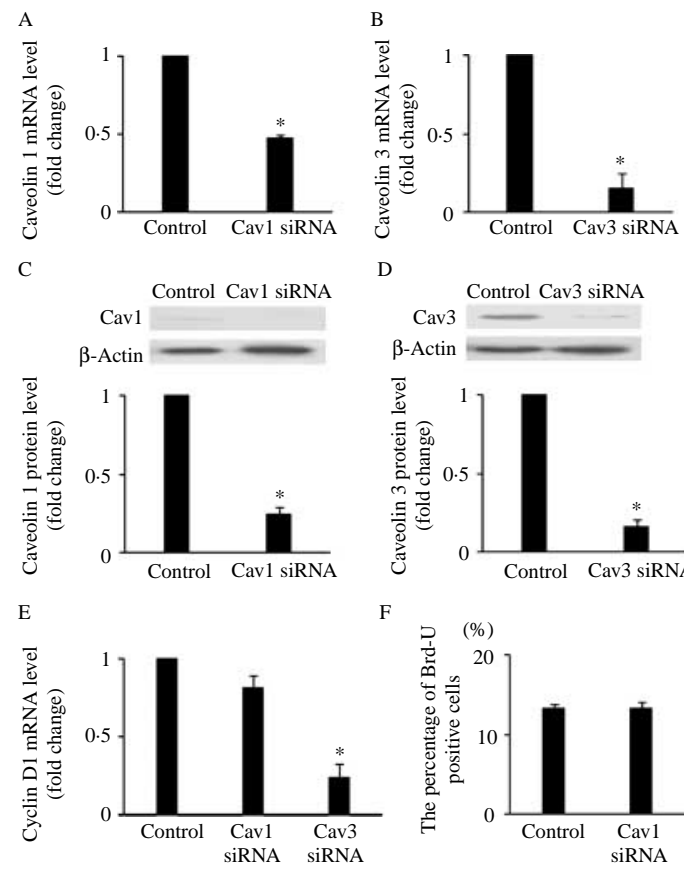

D

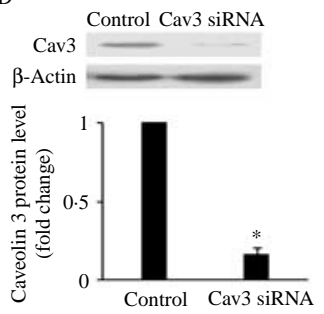

F

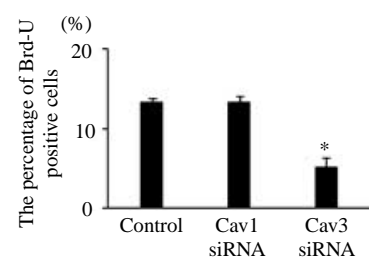

Figure 5 Downregulation of caveolin 1 and 3 by siRNA. (A and B) The expression of caveolin 1 and 3 mRNA determined by real-time PCR was normalized with an internal control (GAPDH) for $48 \mathrm{~h}$ incubation after FS cells were transfected by siRNA respectively (mean \pm s.E.M., $n=4$ ). Caveolin 1 and 3 mRNA levels (Cav 1 siRNA and Cav 3 siRNA) were calculated as ratios of control values (control). Caveolin 1 and 3 mRNA expression of experimental group was lower than that of control. (C and D) The protein levels of caveolin 1 and 3 were determined by western blotting. The upper panel shows caveolin 1 (Cav 1) or 3 (Cav 3 ) and the lower panel shows $\beta$-actin as the loading control. Western blotting data from three experiments (mean \pm S.E.M., $n=3$ ) were quantified by densitometry and normalized with $\beta$-actin. The protein level of caveolin 1 and 3 in FS cells of siRNA treatment (Cav 1 siRNA and Cav 3 siRNA) was significantly lower than that of control (control). (E) Expression of cyclin D1 mRNA determined by real-time PCR was normalized with an internal control (GAPDH) for $48 \mathrm{~h}$ incubation after FS cells were transfected by siRNA. Cyclin D1 mRNA levels in FS cells of caveolin 1 and 3 siRNA treatment (Cav 1 siRNA and Cav 3 siRNA) were calculated as ratios of control values (control) respectively (mean \pm S.E.M., $n=4$ ). (F) The percentage of BrdUpositive cells among FS cells on the laminin-coated surface with siRNA of caveolin 1 and 3 (Cav 1 siRNA and Cav 3 siRNA) respectively. The number of BrdU-positive cells with siRNA of caveolin 3 was significantly lower than that of control (control). $* P<0 \cdot 05$.

epithelial cell, and mesenchymal cells, in the presence of ECM (Schöcklmann et al. 2000, Li et al. 2005, Fernandes et al. 2006). Integrins comprise an $\alpha$-subunit and a $\beta$-subunit that form a heterodimer. In mammals, 18 types of $\alpha$-subunits and eight types of $\beta$-subunits are known; their various combinations give rise to 24 integrin heterodimers that differ in ligand specificity (Hynes 2002). With respect to these ligand specificities, we recently reported that FS cells bind laminin through integrin- $\alpha 3 \beta 1$ and/or integrin- $\alpha 6 \beta 1$ in the

anterior pituitary gland (Horiguchi et al. 2010). As shown in Fig. 2, an antibody that inhibits the integrin $\beta 1$ cascade blocked the increase of ERK phosphorylation and cyclin D1 production, which suggests that integrin $\beta 1$ receives laminin as a signal on FS cells and that its signaling activates MAPK signaling cascades, leading to cyclin D1 transcription and contributing to cell cycle progression. However, there are several signal transduction molecules between integrin $\beta 1$ and MAPK, including focal adhesion kinase (Li et al. 2001, Ding et al. 2009), protein kinase C (Han et al. 2004, Kudirka et al. 2007), and caveolin (Echarri et al. 2007). Caveolin is a cholesterol-binding membrane protein component of caveolae that are small $(50-100 \mathrm{~nm})$ cell invaginations that play a role in numerous cell functions (Parton 2001). Caveolin isoforms 1 and 3 are involved in the formation of
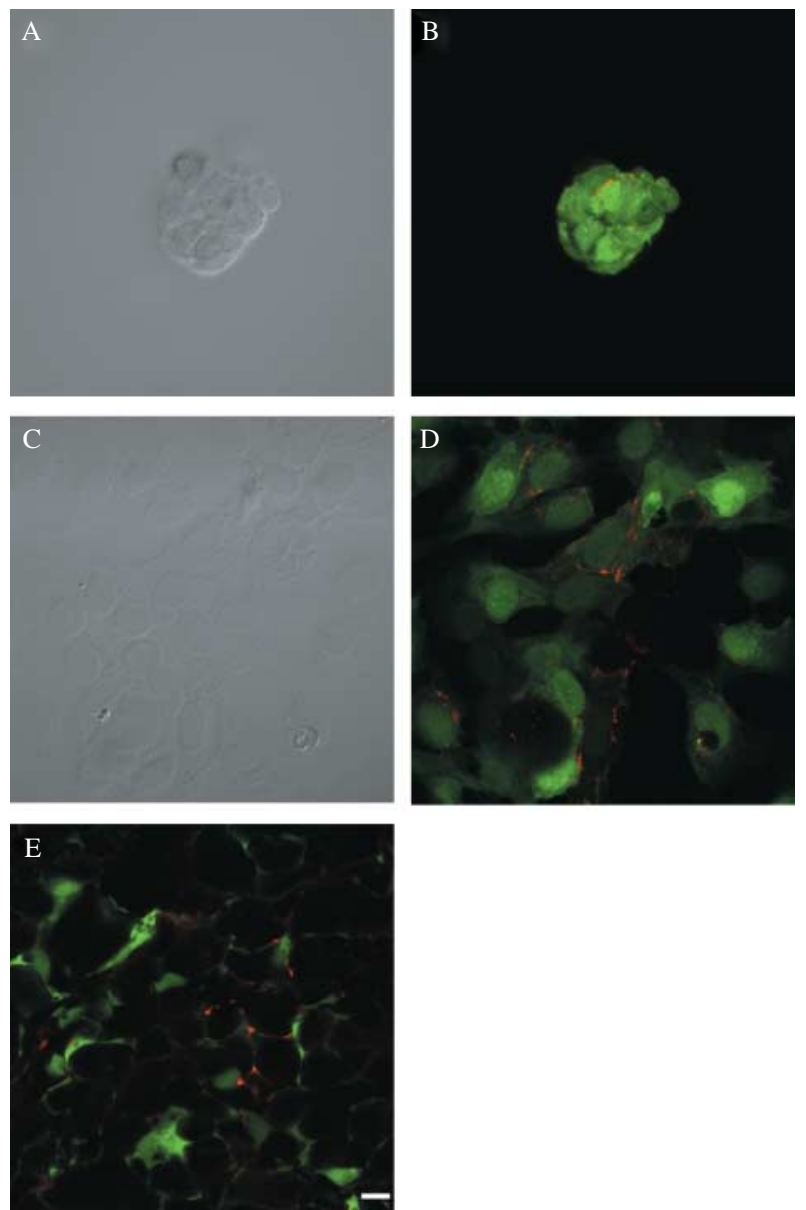

Figure 6 Caveolin 3 expression in anterior pituitary gland. (A-D) Immunocytochemistry for caveolin 3 in primary culture of FS cells; (A and B) $72 \mathrm{~h}$ culture of FS cells on the uncoated surface; (C and D) $72 \mathrm{~h}$ culture of FS cells on the laminin-coated surface; (A and C) phase-contrast images; (B and D) fluorescent images. (E) Immunohistochemistry of caveolin 3 in the anterior pituitary gland. Caveolin 3 (red) immunoreactivity was observed on FS cells (green). Scale bar, $10 \mu \mathrm{m}$. 
caveolae and interact with integrin $\beta 1$ signaling molecules via a specific domain (Echarri et al. 2007). Caveolin 3 is expressed in smooth and skeletal muscle cells, cardiac myocytes, and astrocytes (Song et al. 1996, Ikezu et al. 1998). As shown in Figs 3 and 6, FS cells in anterior pituitary also expressed caveolin 3, and its expression level increased in the presence of laminin. Furthermore, the proliferation of FS cells was inhibited by M $B C D$, which abolishes the distribution of caveolin protein, and by siRNA specific for caveolin 3 (Figs 4 and 5). These results suggest that integrin $\beta 1$ signaling in the proliferation of FS cells was mediated by caveolin 3 . We recently reported that hormoneproducing cells also expressed integrin $\beta 1$ and showed almost no proliferation in the presence of laminin (Horiguchi et al. 2010). Thus, the difference in response to laminin must be due to the expression of caveolin 3. Our findings in this study showed that the caveolin 3-mediated integrin $\beta 1$ signaling pathway was specific to FS cells in anterior pituitary. Integrin $\beta 1$ signaling in the presence of laminin also triggered an increase in gap junction formation between FS cells in our previous report (Horiguchi et al. 2011). There are some reports that caveolin 3 upregulated the expression of connexin 43 in gap junction channel protein (Chung et al. 2009, Liao et al. 2010). This leads us to speculate that caveolin 3 plays a role in gap junction formation between FS cells. In anterior pituitary gland, it has been shown that the lobular structures surrounded by basement membrane are responsible for organizing the functional unit and that the cytoplasmic processes of FS cells attach to the basement membrane (Soji \& Herbert 1989, Shirasawa et al. 2004). In addition to these histological features, we hypothesize that FS cells exert matricrine action via caveolin 3-mediated signaling for their functional roles.

In this study, we observed increased expression of not only caveolin 3 but also caveolin 1, under the influence of laminin in FS cells (Fig. 3). However, caveolin 1 has no effect on the proliferation of FS cells (Fig. 5). Kurzchalia et al. (1992) showed that caveolin 1 is localized to plasma membrane caveolae, the Golgi apparatus, and trans-Golgi-derived transport vesicles. In a previous study, we confirmed by electron microscopy that, in the presence but not in the absence of laminin, FS cells displayed well-developed Golgi apparatus that consisted of several layers of Golgi lamellae and many vesicles and vacuoles in the Golgi area (Horiguchi et al. 2011). These results suggest that the increase in caveolin 1 is due to the hyperfunctional status of FS cells under the influence of laminin.

In a series of studies investigating matricrine action in FS cells (Horiguchi et al. 2010, 2011), we have shown that FS cells in the presence of laminin may play important functional roles in the anterior pituitary gland. In this study, we have succeeded in elucidating the specific mechanism of matricrine action in FS cells. Our findings suggest that proliferation of FS cells is induced by a caveolin 3-mediated integrin $\beta 1$ signaling pathway, leading to activation of the MAPK pathway in the anterior pituitary gland.

\section{Supplementary data}

This is linked to the online version of the paper at http://dx.doi.org/10.1530/ JOE-11-0103.

\section{Declaration of interest}

The authors declare that there is no conflict of interest that could be perceived as prejudicing the impartiality of the research reported.

\section{Funding}

This work was partly supported by a Grant-in-Aid for Scientific Research (C) (21570067 and 22590192), and a Grants-in-Aid for Young Scientists (B) (22790190), from the Ministry of Education, Culture, Sports, Science and Technology of Japan, by promotional funds for the Keirin Race of the Japan Keirin Association, and by the Jichi Medical University Young Investigator Award from Jichi Medical University, School of Medicine.

\section{Acknowledgements}

We thank Prof. K Inoue (Saitama University, Japan) for supplying the transgenic rats. We are grateful to $M$ Yatabe for her excellent technical assistance and to Prof. Y Hanazono and Y Furukawa for their support in fluorescence-activated cell sorting. We also thank David Kipler, ELS, of Supernatant Communications for revising the language of the manuscript.

\section{References}

Allaerts W \& Vankelecom H 2005 History and perspectives of pituitary folliculo-stellate cell research. European Journal of Endocrinology 153 1-12. (doi:10.1530/eje.1.01949)

Bellott AC, Patel KC \& Burkholder TJ 2005 Reduction of caveolin-3 expression does not inhibit stretch-induced phosphorylation of ERK2 in skeletal muscle myotubes. Journal of Applied Physiology 98 1554-1561. (doi:10.1152/japplphysiol.01070.2004)

Chung TH, Wang SM, Liang JY, Yang SH \& Wu JC 2009 The interaction of estrogen receptor alpha and caveolin-3 regulates connexin 43 phosphorylation in metabolic inhibition-treated rat cardiomyocytes. International Journal of Biochemistry \& Cell Biology 41 2323-2333. (doi:10.1016/j.biocel. 2009.06.001)

Ding Q, Gladson CL, Wu H, Hayasaka H \& Olman MA 2009 Focal adhesion kinase (FAK)-related non-kinase inhibits myofibroblast differentiation through differential MAPK activation in a FAK-dependent manner. Journal of Biological Chemistry 283 26839-26849. (doi:10.1074/jbc. M803645200)

Echarri A, Muriel O \& Del Pozo MA 2007 Intracellular trafficking of $\mathrm{raft} / \mathrm{caveolae}$ domains: insights from integrin signaling. Seminars in Cell and Developmental Biology 18 627-637. (doi:10.1016/j.semcdb.2007.08.004)

Fauquier T, Guérineau NC, McKinney RA, Bauer K \& Mollard P 2001 Folliculostellate cell network: a route for long-distance communication in the anterior pituitary. PNAS 98 8891-8896. (doi:10.1073/pnas.151339598)

Fernandes DJ, Bonacci JV \& Stewart AG 2006 Extracellular matrix, integrins, and mesenchymal cell function in the airways. Current Drug Targets 7 567-577. (doi:10.2174/138945006776818700)

Han YS, Bang OS, Jin EJ, Park JH, Sonn JK \& Kang SS 2004 High dose of glucose promotes chondrogenesis via PKC alpha and MAPK signaling pathways in chick mesenchymal cell. Cell and Tissue Research 318 571-578. (doi:10.1007/s00441-004-0993-4)

Horiguchi K, Fujiwara K, Kouki T, Kikuchi M \& Yashiro T 2008 Immunohistochemistry of connexin 43 throughout anterior pituitary gland 
in a transgenic rat with green fluorescent protein-expressing folliculostellate cells. Anatomical Science International 83 256-260. (doi:10.1111/j. 1447-073X.2008.00239.x)

Horiguchi K, Kikuchi M, Kusumoto K, Fujiwara K, Kouki T, Kawanishi K \& Yashiro T 2010 Living-cell imaging of transgenic rat anterior pituitary cells in primary culture reveals novel characteristics of folliculo-stellate cells. Journal of Endocrinology 204 115-123. (doi:10.1677/JOE-09-0333)

Horiguchi K, Kouki T, Fujiwara K, Kikuchi M \& Yashiro T 2011 The extracellular matrix component laminin promotes gap junction formation in the rat anterior pituitary gland. Journal of Endocrinology 208 225-232. (doi:10.1677/JOE-10-0297)

Hynes RO 2002 Integrins: bidirectional, allosteric signaling machines. Cell 110 673-687. (doi:10.1016/S0092-8674(02)00971-6)

Ikezu T, Ueda H, Trapp BD, Nishiyama K, Sha JF, Volonte D, Galbiati F, Byrd AL, Bassell G, Serizawa H et al. 1998 Affinity-purification and characterization of caveolins from the brain: differential expression of caveolin-1, -2 , and -3 in brain endothelial and astroglial cell types. Brain Research 804 177-192. (doi:10.1016/S0006-8993(98)00498-3)

Itakura E, Odaira K, Yokoyama K, Osuna M, Hara T \& Inoue K 2007 Generation of transgenic rats expressing green fluorescent protein in S-100beta-producing pituitary folliculo-stellate cells and brain astrocytes. Endocrinology 148 1518-1523. (doi:10.1210/en.2006-1390)

Kaidzu S, Noda T, Tane N \& Yashiro T 2000 Collagen synthesis by rat anterior pituitary cells in vivo and in vitro. Acta Histochemica et Cytochemica 33 81-87. (doi:10.1267/ahc.33.81)

Kudirka JC, Panupinthu N, Tesseyman MA, Dixon SJ \& Bernier SM 2007 $\mathrm{P} 2 \mathrm{Y}$ nucleotide receptor signaling through MAPK/ERK is regulated by extracellular matrix: involvement of beta3 integrins. Journal of Cellular Physiology 213 54-64. (doi:10.1002/jcp.21087)

Kurzchalia TV, Dupree P, Parton RG, Kellner R, Virta H, Lehnert M \& Simons K 1992 VIP21, a 21-kD membrane protein is an integral component of trans-Golgi-network-derived transport vesicles. Journal of Cell Biology 118 1003-1014. (doi:10.1083/jcb.118.5.1003)

Li W, Duzgun A, Sumpio BE \& Basson MD 2001 Integrin and FAK-mediated MAPK activation is required for cyclic strain mitogenic effects in Caco-2 cells. American Journal of Physiology. Gastrointestinal and Liver Physiology 280 75-87.

Li N, Zhang Y, Naylor MJ, Schatzmann F, Maurer F, Wintermantel T, Schuetz G, Mueller U, Streuli CH \& Hynes NE 2005 Beta1 integrins regulate mammary gland proliferation and maintain the integrity of mammary alveoli. EMBO Journal 24 1942-1953. (doi:10.1038/sj.emboj.7600674)

Liao CK, Wang SM, Chen YL, Wang HS \& Wu JC 2010 Lipopolysaccharideinduced inhibition of connexin43 gap junction communication in astrocytes is mediated by downregulation of caveolin-3. International Journal of Biochemistry \& Cell Biology 42 762-770. (doi:10.1016/j.biocel. 2010.01.016)

Miyamoto S, Nakamura M, Yano K, Ishii G, Hasebe T, Endoh Y, Sangai T, Maeda H, Shi-Chuang Z, Chiba T et al. 2007 Matrix metalloproteinase-7 triggers the matricrine action of insulin-like growth factor-II via proteinase activity on insulin-like growth factor binding protein 2 in the extracellular matrix. Cancer Science 98 685-691. (doi:10.1111/j.1349_ 7006.2007.00448.x)
Paez-Pereda M, Kuchenbauer F, Arzt E \& Stalla GK 2005 Regulation of pituitary hormones and cell proliferation by components of the extracellular matrix. Brazilian Journal of Medical and Biological Research 38 1487-1494. (doi:10.1590/S0100-879X2005001000005)

Parton RG 2001 Cell biology. Life without caveolae. Science 293 2404-2405. (doi:10.1126/science.1065677)

Sato Y, Hashitani H, Shirasawa N, Sakuma E, Naito A, Suzuki H, Asai Y, Sato G, Wada I, Herbert DC et al. 2005 Intercellular communications within the rat anterior pituitary XII: immunohistochemical and physiological evidences for the gap junctional coupling of the folliculo-stellate cells in the rat anterior pituitary. Tissue and Cell 37 281-291. (doi:10. 1016/j.tice.2005.03.005)

Schöcklmann HO, Lang S, Kralewski M, Hartner A, Lüdke A \& Sterzel RB 2000 Distinct structural forms of type I collagen modulate cell cycle regulatory proteins in mesangial cells. Kidney International 58 1108-1120. (doi:10.1046/j.1523-1755.2000.00268.x)

Schultz JF \& Armant DR 1995 Beta 1- and beta 3-class integrins mediate fibronectin binding activity at the surface of developing mouse periimplantation blastocysts. Regulation by ligand-induced mobilization of stored receptor. Journal of Biological Chemistry 270 11522-11531. (doi:10. 1074/jbc.270.19.11522)

Shirasawa N, Mabuchi Y, Sakuma E, Horiuchi O, Yashiro T, Kikuchi M, Hashimoto Y, Tsuruo Y, Herbert DC \& Soji T 2004 Intercellular communication within the rat anterior pituitary gland: X. Immunohistocytochemistry of S-100 and connexin 43 of folliculo-stellate cells in the rat anterior pituitary gland. Anatomical Record. Part A, Discoveries in Molecular, Cellular, and Evolutionary Biology 278 462-473. (doi:10.1002/ar.a. 20040)

Soji T \& Herbert DC 1989 Intercellular communication between rat anterior pituitary cells. Anatomical Record 224 523-533. (doi:10.1002/ ar.1092240410)

Song KS, Scherer PE, Tang Z, Okamoto T, Li S, Chafel M, Chu C, Kohtz DS \& Lisanti MP 1996 Expression of caveolin-3 in skeletal, cardiac, and smooth muscle cells. Caveolin-3 is a component of the sarcolemma and co-fractionates with dystrophin and dystrophin-associated glycoproteins. Journal of Biological Chemistry 271 15160-15165. (doi:10.1074/jbc.271.25. 15160)

Ushio-Fukai M, Hilenski L, Santanam N, Becker PL, Ma Y, Griendling KK \& Alexander RW 2001 Cholesterol depletion inhibits epidermal growth factor receptor transactivation by angiotensin II in vascular smooth muscle cells: role of cholesterol-rich microdomains and focal adhesions in angiotensin II signaling. Journal of Biological Chemistry 276 48269-48275. (doi:10.1074/jbc.M105901200)

\section{Received in final form 7 April 2011 \\ Accepted 20 April 2011}

Made available online as an Accepted Preprint 20 April 2011 